\title{
LA MEDIACIÓN CONCURSAL, ESPECIALIDAD DE LA MEDIACIÓN CIVIL Y MERCANTIL
}

\author{
Autora: Helena Soleto ${ }^{1}$ \\ Profesora Titular de Derecho Procesal, Departamento de Derecho Penal, \\ Procesal e Historia, Instituto Alonso Martínez \\ Universidad Carlos III de Madrid
}

\section{Resumen}

La Ley Concursal recoge una figura preconcursal de carácter mediatorio, el procedimiento extrajudicial de pagos, que permite que los ciudadanos y personas jurídicas, sean o no empresarios, puedan acordar un acuerdo que permita la viabilidad de la actividad personal y profesional. Esta normativa recoge numerosas especialidades, de carácter estructurado y directivo para el procedimiento de mediación, e incluso permite la transformación del papel del mediador en administrador, creando una figura híbrida adecuada para el marco específico del concurso.

\footnotetext{
${ }^{1}$ ORCID http://orcid.org/0000-0001-8283-7354.
} 


\title{
Helena Soleto
}

Palabras clave: mediación; concursal; preconcursal; extrajudicial; ADR; negociación; acuerdo.

\section{The Bankruptcy mediation, specialty of Civil and Commercial Mediation}

\begin{abstract}
The Insolvency Act contains a preconcursal mediatorial figure, the court procedure of payments, which allows citizens and legal persons, whether or not employers, to agree an agreement that allows the viability of personal and professional activity. This rule includes many specialties for the mediation process and even allows the transformation of the role of mediator into administrator, creating a hybrid figure appropriate for the specific context of bankruptcy.
\end{abstract}

Key words: mediation; bankruptcy; extrajudicial; ADR; negotiation; agreement.

Recibido: $21 / 04 / 2016$

Aceptado: 11/07/2016

\section{1. ¿POR QUÉ UNA MEDIACIÓN CONCURSAL ESPECIAL?}

Mucho se ha avanzado en el ámbito de la mediación desde que en España esperábamos la trasposición de la Directiva 2008/52/CE del Parlamento Europeo y del Consejo, de 21 de mayo de 2008, sobre ciertos aspectos de la mediación en asuntos civiles y mercantiles, DOUE núm. 136, de 24 de mayo de 2008, que a su vez se tramitaba desde 2004 .

La mediación ha pasado de ser una completa desconocida a una institución asumida por el sistema jurídico. Rechazada inicialmente por juristas de distintas ubicaciones, se ha ido integrando en el sistema, si bien la frecuencia de su uso práctico queda por comprobar.

La Ley 5/2012, de 6 de julio, de mediación en asuntos civiles y mercantiles (BOE núm. 162, de 7 de julio de 2012), es la primera regulación de la mediación a nivel estatal, que fue precedida por regulaciones de diversas Comunidades Autónomas, que se centraban en la mediación familiar, aunque en los años previos a la Ley de 2012 ya algunas se extendían al ámbito civil general.

La Ley de 2012 fue complementada por el Reglamento en 2013 (Real Decreto 980/2013, de 13 de diciembre, por el que se desarrollan determinados aspectos de la Ley 5/2012, de 6 de julio, de mediación en asuntos civiles y mercantiles, BOE 
núm. 310, de 27 de diciembre de 2013), que detalló cuestiones relativas a la inscripción en el Registro del Ministerio de Justicia de los mediadores, instituciones de mediación y otras cuestiones administrativas.

Dicha Ley vino a regular de forma bastante extensa los principios de la mediación, el procedimiento de mediación y la relación de éste con el proceso judicial, si bien se excluyeron algunos ámbitos materiales de dicha regulación en su artículo 2.2.: la mediación penal, la laboral, la administrativa y la mediación en consumo fueron excluidas por el legislador, cuestión bastante criticada por la doctrina.

El ámbito de la mediación concursal no queda excluido del ámbito de la Ley de 2012, es por lo tanto esta Ley su regulación básica, complementada por lo establecido por la Ley Concursal, la cual ha sido modificada por sucesivas Leyes, recogiendo la figura del mediador concursal y las especiales relaciones del procedimiento de mediación con el proceso de concurso.

La Ley Concursal (Ley Orgánica 8/2003, de 9 de julio, para la Reforma Concursal, por la que se modifica la Ley Orgánica 6/1985, de 1 de julio, del Poder Judicial, BOE núm. 164, de 10 de julio de 2003) ha sido modificada frecuentemente, principalmente por el marco de la grave crisis económica que afecta España, con el objetivo general de reactivar la economía y la mejora de los procedimientos de concurso, introduciendo en las últimas reforma la figura del deudor persona física y procurando la consecución de un acuerdo para evitar el concurso².

De entre las numerosas modificaciones que ha sufrido la Ley Concursal en 12 años, son las producidas a partir de la modificación en 2013 las que introducen y abordan la mediación.

En cuanto a la pregunta, ¿por qué una regulación especial sobre mediador concursal y mediación concursal?, la respuesta está en la complejidad de los procedimientos concursales y las especiales imbricaciones con el proceso concursal del propio procedimiento de acuerdo.

Y en cuanto a la necesidad o no de una regulación específica, consideramos que el marco de la ley de 2012 es suficientemente generoso para haberse aplicado sin más a la mediación concursal, sin embargo, entendemos que varias circunstancias apoyan la regulación específica de la institución, como pueden ser, entre otros:

- La preocupación de los operadores y el legislador por los efectos de la crisis económica en la destrucción de las empresas, y su intención en ofrecer mecanismos que procuraran su viabilidad, evitando el concurso.

- La misma preocupación respecto de la situación económica de los particulares.

${ }^{2}$ Enciso Alonso-Muñumer, M. T., "Acuerdo extrajudicial de pagos y segunda oportunidad”, en VV. AA., La Ley concursal y la Mediación Concursal: un estudio conjunto realizado por especialistas, Dykinson, Madrid, 2014, se refiere a que si bien la ley de 2003 puso fin al caos normativo, su aplicación desde entonces ha hecho aflorar sus deficiencias, como la excesiva judicialización del procedimiento y falta de flexibilidad. 


\section{Helena Soleto}

- La especial complejidad de los conflictos relacionados con la crisis económica de la empresa, dado por factores como la multiplicidad de participantes, la relación de prevalencia de determinados acreedores en virtud de las garantías establecidas o la naturaleza de la deuda, entre otros, que, sin una especial regulación que ordene el procedimiento y el papel de cada clase de participantes, supondrían la imposibilidad de iniciar la mediación.

- La complejidad del procedimiento concursal, y la necesidad de relacionar con éste el resultado de la mediación, tanto si hay acuerdo como si no.

- La constatación de que el perfil más adecuado del mediador concursal debería ser el de alguien especializado, precisamente por las complejidades citadas. ${ }^{3}$

\section{LA MEDIACIÓN EN LA LEY CONCURSAL}

Las más importantes modificaciones de la Ley Concursal en torno a la mediación se produjeron por dos normas: a través de la Ley 14/2013, de 27 de septiembre, de apoyo a los emprendedores y su internacionalización, BOE núm. 233, de 28 de septiembre de 2013, se introduce el Título X de la Ley Concursal, dedicado al acuerdo extrajudicial de pagos, y en 2015 se recogen adaptaciones en base a Ley de Real Decreto-Ley 1/2015, de 27 de febrero, de mecanismo de segunda oportunidad, reducción de carga financiera y otras medidas de orden social, para permitir el uso de los mecanismos por las personas naturales no empresarios ${ }^{4}$.

La Ley Concursal ofrece, como indica Senés, un instituto preconcursal que no debería haberse calificado como mediación concursal, sino, como señala Prats, mediación preconcursal ${ }^{5}$.

Este mecanismo de mediación existe en el marco de la normativa sobre mediación civil y mercantil de 2012, con unas características especiales en cuanto tres cuestiones principalmente:

\footnotetext{
${ }^{3}$ Vid. Ordeñana, I., "El fin justifica...La mediación concursal empresarial o profesional: sobre la función y regulación de este mecanismo extrajurisdiccional en el derecho español", en Barona Vilar, S., (coord.), Mediación, arbitraje y jurisdicción en el actual paradigma de justicia, Thomson Reuters-Civitas, Pamplona, 2016, pp. 119-145.

${ }^{4}$ Vid. el preámbulo I de dicha norma, en la que se justifica el cambio de paradigma respecto de las deudas de los particulares, y las consecuentes medidas como el beneficio de la exoneración del pasivo insatisfecho, vinculado también al intento del procedimiento de acuerdo extrajudicial de pagos, institución al que a partir de esta norma puede acudir el deudor persona natural no empresario. Senés Motilla, M. C., "El acuerdo extrajudicial de pagos: ¿alternativa efectiva al concurso de acreedores?", Revista de Derecho Civil, (núm..1, enero-marzo 2014), p. 52, ya señalaba la conveniencia de ampliar el mecanismo a los consumidores, a las personas no empresarias.

${ }^{5}$ Senés Motilla, M. C., "El acuerdo...", cit., p. 51. Prats Albentosa, L., "La mediación (pre)-concursal", Diario La Ley, (núm. 8264, 2014), p. 1.
} 
- En primer lugar, sobre requisitos de capacitación del mediador, que ha de tener la cualificación de administrador concursal si también pretende desarrollar actividades de administración concursal.

- En segundo lugar, en relación con el procedimiento, concretamente en la solicitud y nombramiento del mediador y la toma de acuerdos.

- En tercer lugar, en cuanto a la posibilidad de reconvertir la función del mediador a administrador concursal, en una suerte de fórmula parecida a la del medarb.

\subsection{Especialidades relativas a la figura del mediador}

\subsubsection{Cualificación}

El mediador concursal ostenta algunas especialidades frente al mediador civil:

En relación con su cualificación, en el artículo 233.1 de la Ley Concursal se hace referencia a la cualificación como mediador y también a la de administrador concursal: "El nombramiento de mediador concursal habrá de recaer en la persona natural o jurídica a la que de forma secuencial corresponda de entre las que figuren en la lista oficial que se publicará en el portal correspondiente del "Boletín Oficial del Estado", la cual será suministrada por el Registro de Mediadores e Instituciones de Mediación del Ministerio de Justicia. El mediador concursal deberá reunir la condición de mediador de acuerdo con la Ley 5/2012, de 6 de julio, de mediación en asuntos civiles y mercantiles, y, para actuar como administrador concursal, las condiciones previstas en el artículo 27 "6.

Hay que aclarar que en el artículo 233 no se exige que el mediador haya de reunir la condición de mediador más las exigencias del artículo 27 de la propia Ley, esto es, la condición de administrador concursal, pero se establece que para que el mediador actúe como administrador concursal en el caso de que al acuerdo fallido o ineficaz le siga el concurso habrá de cumplir los requisitos del artículo 27. El práctico automatismo del nombramiento como administrador al anterior mediador concursal para el caso de que no tuviera éxito el procedimiento de acuerdo aconsejará que se elijan personas que tengan las dos cualificaciones.

\subsubsection{Estilo del mediador}

Aunque sigue siendo debatido el papel del mediador civil en cuanto a si ha de ser facilitador o directivo, incluso evaluativo (estos dos últimos términos pueden ser

\footnotetext{
${ }^{6}$ En cuanto a las particularidades del "sistema público de regulación del ejercicio de la actividad profesional del mediador" de la Ley de mediación, y la obligación para el mediador concursal frente al derecho genérico de listas de mediadores, Véase Prats, L., cit., pp. 3 y ss.
} 


\section{Helena Soleto}

incluso análogos ${ }^{7}$ ), en principio para llevar a cabo una mediación civil en la que las partes están bien informadas, a través de sus asesores, no es preciso que el mediador tenga conocimientos sobre la materia. Otra cuestión es si las partes eligen un modelo de mediador que sea evaluativo, que ofrezca su opinión, opciones de solución, etc.

Pues bien, no entrando en el modelo de mediación que el mediador habrá de desempeñar, y pese a que es cierto que cualquier mediador puede llevar a cabo una mediación sin tener conocimientos sobre la materia objeto de conflicto, en el ámbito concursal el legislador ha entendido que la complejidad del procedimiento concursal y las graves consecuencias que puede tener la actividad de un sujeto no informado apoyan la elección de un mediador fuertemente informado sobre la materia concursal, de ahí que en sistema diseñado en la Ley Concursal se favorezca la elección de un mediador concursal que tenga las condiciones para actuar como administrador concursal.

Algunos autores consideran que un estilo evaluativo lleva a la mediación a no serlo, y convertirse en una fórmula híbrida ${ }^{8}$, sin embargo, consideramos que la mediación concursal no es una fórmula híbrida sino un mecanismo mediatorio con especialidades normativas que reflejan la especialidad del objeto de la mediación, y que puede considerarse híbrida en conjunto con la función de administración concursal si se dan las circunstancias establecidas normativamente.

En cuanto a su forma de trabajo, el procedimiento descrito en la Ley Concursal apoya un desarrollo directivo y evaluativo de la mediación, en cuanto al procedimiento, el mediador ha de ser directivo, tener la iniciativa en la ordenación del procedimiento, pero también en cuanto al fondo: la primera propuesta que ha de presentar el mediador es preparada por él con el acuerdo del deudor, y tanto en ésta como en los sucesivos trámites la normativa asume que el mediador concursal tiene opiniones fundadas, dado que ha evaluado la situación, y que ha de defender frente a los demás participantes.

\subsection{Especialidades del procedimiento de mediación concursal}

El procedimiento de mediación concursal se distancia de un procedimiento ordinario de mediación en varios puntos que se abordarán en los apartados siguientes:

- la solicitud para iniciarse sólo la tiene el deudor;

- el inicio se declara por una de tres instituciones posibles: Registrador Mercantil, Notario y Cámara;

${ }^{7}$ Vid. Riskin, L., "Decisionmaking in Mediation: The New Old Grid and the New New Grid System", Notre Dame Law Review, (vol. 79, núm. 1, 2003), así como Soleto Muñoz, H., "El procedimiento de mediación”, en Soleto Muñoz, H. (dir.), Carretero Morales, E. y Ruiz López, C. (coord..), Mediación y solución de conflictos: técnicas y ámbitos, Tecnos, Madrid, 2013, pp. 261-268.

${ }^{8}$ San Juan Muñoz, E., "La naturaleza jurídica del mediador concursal: sistema alternativo de gestión de los supuestos de insolvencia”, Diario la Ley, (núm. 8230, 2014), p. 3. 
- el mecanismo de nombramiento de mediador es variado dependiendo de la institución competente para declarar el inicio del procedimiento;

- puede ser nombrada una comisión en vez de un solo mediador (sólo en el marco de la competencia de la Cámara);

- la fase de negociación es asíncrona salvo por la reunión final;

- el mediador prepara propuestas de acuerdo autorizadas por el deudor;

- una de las partes está formada por una pluralidad de partes y el resultado puede afectar a todas aunque no hayan aprobado el acuerdo;

- existen una serie de reglas de mayorías cualificadas para la aprobación del acuerdo.

\subsection{La transformación de mediador en administrador concursal}

La regulación más innovadora que contiene la Ley Concursal es el nombramiento como administrador concursal al mediador cuando no tenga resultado eficaz el procedimiento de acuerdo, otorgando así un importante estatus al mediador, que será administrador y gestionará la liquidación en el caso de que la primera fase no sea exitosa.

Esta dualidad de roles en la misma persona ya ha sido cuestionada en la fórmula de medarb, en la que la mediación sería seguida por un arbitraje si la primera no tuviera éxito.

Los inconvenientes se refieren a la confidencialidad: por una parte, las partes pueden no tener confianza en un mediador que luego va a ser decisor y, por otra, en la dificultad de preservar la confidencialidad de lo conocido en la fase de mediación en la de administración?

En relación con el riesgo de falta de confianza de las partes, en el marco de una mediación en la que el conflicto es únicamente económico, y el objetivo es que las partes realicen concesiones, pocas cuestiones serán conflictivas a efecto de confidencialidad. Además, si el mediador tiene la capacitación adecuada, será capaz de distinguir perfectamente sus funciones en cada una de las etapas.

\section{LA MEDIACIÓN: EL PROCEDIMIENTO EXTRAJUDICIAL DE PAGOS}

\subsection{Presupuestos de admisión}

El procedimiento de acuerdo extrajudicial de pagos que se describe en el artículo 232 de la Ley Concursal es un procedimiento de mediación al que se

${ }^{9}$ Ortiz Hernández, A., "La mediación en el concurso de acreedores”, Diario la Ley, (núm. 8111, 2013), p. 1, se manifiesta en contra de la atribución de las dos funciones a la misma persona en base a la pérdida de neutralidad y a la de confidencialidad. 


\section{Helena Soleto}

ha de llegar a través de ciertas actividades procedimentales y en unos casos determinados.

Se excluyen del procedimiento asuntos en virtud de la naturaleza de los acreedores, así como por condiciones personales de los deudores. Así, en relación con acreedores, se excluyen los casos en los que son acreedores las Administraciones públicas.

En lo que toca a los deudores, las exclusiones son más amplias: se excluyen las personas que hayan sido condenadas por delitos que puedan tener relación con la actividad económica ${ }^{10}$, los que ya hubieran realizado acuerdos análogos en los 5 últimos años ${ }^{11}$ y los que se encuentren en una fase inicial de concurso o de negociación ${ }^{12}$. Las aseguradoras y las reaseguradoras están excluidas de acuerdo con lo establecido en el artículo 231.5, sin embargo el apartado introducido en la Ley Concursal por la Ley 20/2015, de 14 de julio, sí admite la mediación entre entidades aseguradoras, al disponerse en el artículo 233.5 que "En el caso de entidades aseguradoras, el mediador designado deberá ser el Consorcio de Compensación de Seguros".

Además, por falta de adecuación, se excluyen del procedimiento los asuntos que ya se estén negociando, así como aquellos en los que el Juzgado haya admitido a trámite la solicitud de concurso (art. 231.4 LC).

La Ley permite que acudan a este procedimiento las personas físicas y jurídicas, que en ambos casos podrán ser a su vez empresarios o no empresarios.

Los requisitos y procedimiento varían en virtud de la naturaleza de la persona y el carácter de empresario o no.

\subsubsection{Siendo deudor una persona física}

La Ley Concursal regula los requisitos para el procedimiento extrajudicial de la persona física, que puede a su vez ser empresario o no, lo que conllevará especialidades.

La persona natural empresaria a los efectos de la Ley será no sólo la considerada como tal por la normativa mercantil, sino también las personas que ejerzan

10 “231.3. No podrán formular solicitud para alcanzar un acuerdo extrajudicial de pagos: $1 .^{\circ}$ Quienes hayan sido condenados en sentencia firme por delito contra el patrimonio, contra el orden socioeconómico, de falsedad documental, contra la Hacienda Pública, la Seguridad Social o contra los derechos de los trabajadores en los 10 años anteriores a la declaración de concurso".

11 "2231.3.2. ${ }^{\circ}$ Las personas que, dentro de los cinco últimos años, hubieran alcanzado un acuerdo extrajudicial de pagos con los acreedores, hubieran obtenido la homologación judicial de un acuerdo de refinanciación o hubieran sido declaradas en concurso de acreedores.

El cómputo de dicho plazo comenzará a contar, respectivamente, desde la publicación en el Registro Público Concursal de la aceptación del acuerdo extrajudicial de pagos, de la resolución judicial que homologue el acuerdo de refinanciación o del auto que declare la conclusión del concurso".

12 "321.4. No podrán acceder al acuerdo extrajudicial de pagos quienes se encuentren negociando con sus acreedores un acuerdo de refinanciación o cuya solicitud de concurso hubiera sido admitida a trámite". 
actividades profesionales, las que sean clasificados como empresarios por la seguridad social y los autónomos (art. 232 LC).

La persona natural no empresaria también podrá iniciar el procedimiento, regulándose las especialidades en el artículo 342 bis, que afectan principalmente a la competencia y a la reducción de los plazos.

De esta forma, se introduce la posibilidad de que personas naturales que en la práctica gestionen o no su actividad de trabajo en el mundo mercantil puedan acogerse al procedimiento de mediación.

Los requisitos para que la persona natural pueda ser parte en el procedimiento de mediación son:

- que se encuentre en situación de insolvencia o prevea que no podrá cumplir regularmente con sus obligaciones;

- que la cantidad impagada o que no vaya a ser pagada no supere los 5 millones de euros;

- que si es empresario, aporte el balance correspondiente.

Además, la Ley contempla especialidades si la persona está casada:

- si estuviera casada en régimen distinto al de separación de bienes, señalará cuál es y aportará la identidad del cónyuge ${ }^{13}$;

- si la vivienda familiar en propiedad pudiera verse afectada por el acuerdo, habrá de realizarse una solicitud conjunta o aportar el consentimiento del otro cónyuge.

En la norma se hace referencia también, en caso de tener un régimen distinto a separación de bienes, y tuviera obligación legal -por su profesión se entiendede llevar contabilidad, que se aporten las cuentas anuales de los últimos tres años. No es muy clara la dicción del artículo, parece ser una exigencia para el cónyuge del solicitante, algo intrusiva con su intimidad dado que no es parte del procedimiento salvo que tuviera una vivienda común que pudiera verse afectada, pero justificable en base a la vinculación de los derechos y obligaciones económicas de los cónyuges. En todo caso, quizá esta prevención es muy poco práctica, y por ello no ha sido recogida en el formulario de solicitud aprobado por el Ministerio de Justicia.

\subsubsection{Siendo deudor una persona jurídica}

En la Ley Concursal se establece que la persona jurídica puede optar al procedimiento de mediación, siempre que:

- se encuentre en estado de insolvencia;

13 "Si el deudor fuere persona casada, salvo que se encuentre en régimen de separación de bienes, indicará la identidad del cónyuge, con expresión del régimen económico del matrimonio, y si estuviera legalmente obligado a la llevanza de contabilidad, acompañará asimismo las cuentas anuales correspondientes a los tres últimos ejercicios". 


\section{Helena Soleto}

- no se trate de un asunto excesivamente complejo (se hace referencia a que para el caso de que se declarara su el concurso no sería complejo ex. art. 190, del procedimiento abreviado, que limita a 5 euros el pasivo y a 50 el número de acreedores) $)^{14}$;

- pueda satisfacer los gastos del acuerdo.

El ámbito de exclusión para la persona jurídica es amplio en relación con el concurso si se tiene en cuenta lo señalado en el apartado 3 y el 4 del mismo artículo, pues se hace referencia a la solicitud y declaración de concurso: según el apartado 4, no podría participar si ha sido admitida a trámite la solicitud de concurso y según el 3 tampoco si ha sido declarada en concurso.

\subsection{Legitimación y competencia}

\subsubsection{Legitimación: el deudor como único solicitante posible}

A diferencia de la mediación civil y mercantil general, en el procedimiento extrajudicial de acuerdo, el deudor es el único solicitante del procedimiento.

La Ley de mediación de 2012 se refiere a la solicitud de las partes de mutuo acuerdo o de una de ellas en virtud de un pacto previo (art. 16), e incluso a la invitación a mediación por parte del órgano jurisdiccional del artículo 440 LEC, sin embargo, en el procedimiento especial mediatorio de la Ley Concursal se limita la legitimación para solicitar la iniciación del procedimiento al deudor, que además deberá de acompañar una documentación específica a su solicitud.

Nada obsta a que otras personas distintas al deudor intenten iniciar una mediación, pero en este caso nos encontraremos con una mediación regulada en la Ley de 2012 y no con una mediación concursal, y por lo tanto podrá tener unos efectos mucho más limitados.

\subsubsection{La solicitud}

En el artículo 232 se describe de forma poco clara el objeto de la solicitud: dicho artículo se titula "solicitud de acuerdo extrajudicial de pagos", y en el apartado 1 se establece que "El deudor que pretenda alcanzar con sus acreedores un acuerdo extrajudicial de pagos solicitará el nombramiento de un mediador concursal".

\footnotetext{
${ }^{14}$ Merino Espinar, M. B., "Una primera aproximación a la realidad del acuerdo extrajudicial de pagos y la figura del mediador concursal y su relación con el Registro de la Propiedad", Revista de Derecho Civil, (vol. II, núm. 1, enero 2015), p. 178, defiende la conveniencia de que se exigieran los mismos requisitos a todos los deudores.
} 
La solicitud entonces podrá ser de iniciar un procedimiento para conseguir un acuerdo extrajudicial de pagos, o más exactamente habrá de ser una solicitud de nombramiento de mediador para conseguir un acuerdo extrajudicial de pagos.

La forma de solicitud se detalla en el artículo 232.2, a través de un formulario normalizado, aunque también en el 232.3 se hace referencia a la solicitud telemática al Registro Mercantil, que habrá de corresponderse en el contenido con lo dispuesto en el 232.215.

La solicitud, según esta norma, habrá de acompañarse de la siguiente información, también en formato normalizado del Ministerio de Justicia ${ }^{16}$ :

- inventario con activos e ingresos previstos;

- lista de acreedores, con cuantía y vencimiento de los créditos.

\subsubsection{Institución competente para la decisión}

Curiosamente en la Ley Concursal se establecen varias instituciones diferentes para ser competente de la decisión de admisión del asunto para ser tramitado como procedimiento extrajudicial de acuerdo, a elegir por parte del deudor, único iniciador del procedimiento.

Es posible que hayan sido intereses de grupos los que han producido una regulación tan pintoresca, en la que los Registradores, los Notarios y las Cámaras en sus diversas configuraciones han sido los destinatarios de estas solicitudes y decisiones ${ }^{17}$.

La Ley distingue las solicitudes realizadas por persona natural de las de la persona jurídica y de la condición de empresario:

Si se trata de persona jurídica o natural empresaria, será competente el Registrador Mercantil (art. 232.3. I), pero también podrá ser competente la

15 "La solicitud se hará mediante formulario normalizado suscrito por el deudor e incluirá un inventario con el efectivo y los activos líquidos de que dispone, los bienes y derechos de que sea titular y los ingresos regulares previstos. Se acompañará también de una lista de acreedores, especificando su identidad, domicilio y dirección electrónica, con expresión de la cuantía y vencimiento de los respectivos créditos, en la que se incluirán una relación de los contratos vigentes y una relación de gastos mensuales previstos. Lo dispuesto en el artículo $164.2 .2^{\circ}$ será de aplicación, en caso de concurso consecutivo, a la solicitud de acuerdo extrajudicial de pagos.

El contenido de los formularios normalizados de solicitud, de inventario y de lista de acreedores, se determinará mediante orden del Ministerio de Justicia.

Esta lista de acreedores también comprenderá a los titulares de préstamos o créditos con garantía real o de derecho público sin perjuicio de que puedan no verse afectados por el acuerdo. Para la valoración de los préstamos o créditos con garantía real se estará a lo dispuesto en el artículo 94.5”

${ }^{16}$ El formulario abarca la solicitud, la lista de acreedores y el inventario. Accesible en http://www. boe.es/boe/dias/2015/12/29/pdfs/BOE-A-2015-14225.pdf

${ }^{17}$ Senés Motilla, C., "El acuerdo extrajudicial de pagos: ‘alternativa efectiva al concurso de acreedores?", Revista de Derecho Civil, (núm.1, enero-marzo 2014), p. 50, se hace eco de las críticas que la Ley de 2013 que introdujo este mecanismo y competencia produjo además de por sus deficiencias técnicas, por el favorecimiento a determinados sectores profesionales. 


\section{Helena Soleto}

Cámara (art. 232.3. II), por lo que hay competencia concurrente de Registrador Mercantil y Cámaras, y podrá elegir entonces el deudor a qué institución dirigirse.

En cuanto a la persona física no empresario (autónomos etc), la competencia corresponde a los Notarios exclusivamente (art. 242 bis $1.1^{\circ}$.) ${ }^{18}$.

La regulación sobre la actuación de la Institución supone que es casi automática, aunque atemperada en el artículo 242 bis en lo relativo a la solicitud por personas naturales no empresarias: "una vez constatada la suficiencia de la documentación aportada y la procedencia de la negociación del acuerdo extrajudicial de pagos". Señalaba Merino antes de la reforma que introdujo el 242 bis que sería adecuado aprovechar a los profesionales Registrador y Notario en esta fase para un control de la adecuación, pues bien, en relación con el Notario ya se encuentra regulado, y en cuanto a las demás instituciones entendemos que debería ser igualmente aplicable, al menos respecto del Registrador.

Por otra parte, nada se indica en la norma concursal en cuanto al rechazo por la institución de la solicitud de iniciación del procedimiento. Señala Merino ${ }^{19}$ que habrá de aplicarse el régimen general de recursos contra las calificaciones negativas del Registrador Mercantil o contra las inadmisiones de actuación del notario a requerimiento del interesado de la Ley notarial. En cuanto a las Cámaras de Comercio, entendemos que ante su negativa el interesado podría acudir con una nueva solicitud al Registro.

\subsubsection{Nombramiento de mediador}

Otra importante curiosidad de la fase inicial del procedimiento extrajudicial es la forma de nombramiento del mediador: en alguno de los casos, es posible que la propia institución asuma las labores de mediación. Esta atribución también

${ }^{18}$ La Orden del Ministerio de Justicia Orden JUS/2831/2015, de 17 de diciembre, por la que se aprueba el formulario para la solicitud del procedimiento para alcanzar un acuerdo extrajudicial de pagos, BOE núm. 311, de 29 de diciembre de 2015, en su artículo 2, contiene una redacción más clara que la Ley Concursal: "1. La solicitud del deudor no empresario, tanto persona natural como jurídica, irá dirigida al notario correspondiente a su domicilio. 2. En caso de que el deudor sea empresario o entidades inscribibles en el Registro Mercantil podrá optar por dirigir la solicitud al registrador mercantil correspondiente a su domicilio o a la Cámara Oficial de Comercio, Industria, Servicios y Navegación cuando hayan asumido funciones de mediación de conformidad con su normativa específica o a la Cámara Oficial de Comercio, Industria, Servicios y Navegación de España, de conformidad con el artículo 232.3 de la Ley Concursal. 3. La solicitud se podrá presentar a través de los medios electrónicos que se habiliten por los órganos que se indican en este artículo. 4. La solicitud de iniciación del procedimiento para alcanzar un acuerdo extrajudicial de pagos, así como los trámites notariales o registrales previstos en el artículo 233 para el nombramiento del mediador concursal, no conllevarán coste alguno para las personas naturales no empresarios".

${ }^{19}$ Merino Espinar, M. B., “Una primera...”, cit., p. 180. 
puede achacarse a presiones e intereses de grupo, no justificables en una sociedad democrática desarrollada.

El principio de predeterminación del juzgador que inspira nuestro ordenamiento no es completamente extrapolable en la elección de un mediador por una institución, pero cuando tiene unas competencias e incluso un poder tan importante como el establecido en la Ley Concursal, debería asegurarse la transparencia en la tramitación y la predeterminación reglamentaria de las personas elegidas, tal como se hace por el mecanismo atribuido al Registro Mercantil.

La atemperación de que la elección de órgano decisor competente pueda hacerse también a los Registradores no es suficiente para impedir la falta de transparencia del sistema, dado que la elección del órgano corresponde al deudor.

\section{a) Nombramiento por el Registro Mercantil}

En el artículo 233 de la Ley Concursal se establecen la forma de elección del mediador concursal de forma predeterminada y transparente, a través de parámetros razonables y comprobables:

"El nombramiento de mediador concursal habrá de recaer en la persona natural o jurídica a la que de forma secuencial corresponda de entre las que figuren en la lista oficial que se publicará en el portal correspondiente del "Boletín Oficial del Estado", la cual será suministrada por el Registro de Mediadores e Instituciones de Mediación del Ministerio de Justicia”.

\section{b) Nombramiento por las Cámaras: autonombramiento}

La norma, en el artículo 233.3 recoge el curioso mecanismo de autonombramiento en el marco de las Cámaras al que nos referíamos: "Cuando la solicitud se haya dirigido a una Cámara Oficial de Comercio, Industria, Servicios y Navegación o a la Cámara Oficial de Comercio, Industria, Servicios y Navegación de España, la propia Cámara asumirá las funciones de mediación conforme a lo dispuesto en la Ley 4/2014, de 1 de abril, Básica de las Cámaras Oficiales de Comercio, Industria, Servicios y Navegación y designará una comisión encargada de mediación, en cuyo seno deberá figurar, al menos, un mediador concursal".

En el caso de la gestión del procedimiento por la cámara de comercio, no se dispone el nombramiento de un solo mediador sino de una "comisión", entre los que se encontrará un mediador concursal, se entiende de los de la lista del Boletín Oficial del Estado, pero sin exigencia de que sea el que correspondiere por orden, es decir, que podrá ser cualquiera de los que están en la lista, además de otras personas de cuya capacitación nada se señala, si bien se entiende que al menos cumplir de tener las exigencias de la Ley de 2012. 


\section{Helena Soleto}

\section{c) Nombramiento por el Notario}

En la Ley Concursal, en el artículo 242 bis, se recoge una especialidad también muy curiosa en cuanto al nombramiento del mediador por parte del notario: por un lado, se faculta al notario a realizar labores de auxilio a la negociación de las partes, evitándose incluso la mediación, o más bien asumiendo el notario funciones pseudomediadoras: "El notario impulsará las negociaciones entre el deudor y sus acreedores, pudiendo designar, si lo estima conveniente o lo solicita el deudor, un mediador concursal. El nombramiento del mediador concursal deberá realizarse en los cinco días siguientes a la recepción por el notario de la solicitud del deudor".

Se entiende que el notario, en caso de nombrar mediador, habrá de seguir los parámetros del artículo 233.1 que describíamos en el apartado correspondiente al nombramiento por los Registradores, es decir, habrá de nombrar a los mediadores de la lista oficial del BOE.

En cuanto a la remuneración del notario cuando realice el apoyo a las negociaciones de las partes, por una parte, la dicción del 242 bis $1.4^{\circ}$. excluye el cobro para notarios y registradores por las actividades del artículo 233, y por otra, si el notario realizara las actividades pseudomediatorias sin nombrar un mediador podría cobrar las cantidades previstas para el mediador concursal, según lo previsto en el artículo 242 bis.

\subsubsection{Comunicaciones tras el nombramiento}

Una vez que la institución a la que se dirige la solicitud nombra al mediador competente, y éste acepta o rechaza el nombramiento, ha de realizar varias comunicaciones, a instituciones públicas y a acreedores:

- comunicará al Juez la apertura de negociaciones;

- ordenará la publicación de la apertura de negociaciones al Registro Público Concursal;

- comunicará a los registros públicos de bienes la apertura del procedimiento para que se realice anotación preventiva ${ }^{20}$;

- comunicará a Agencia Tributaria y a la Seguridad Social el inicio del procedimiento, con los datos del mediador y el deudor;

- comunicará a la representación de los trabajadores el inicio del procedimiento y les hará saber su derecho a personarse en el procedimiento.

20 "Dará cuenta del hecho por certificación o copia remitidas a los registros públicos de bienes competentes para su constancia por anotación preventiva en la correspondiente hoja registral, así como al Registro Civil y a los demás registros públicos que corresponda, comunicará de oficio la apertura de negociaciones al juez competente para la declaración de concurso y ordenará su publicación en el Registro Público Concursal". 
La Ley también se refiere a la comunicación al Registro Civil, si bien de acuerdo con el artículo 72.2 de la Ley del Registro civil sólo se podrán inscribir la declaración de concurso y otras decisiones de mayor calado, como la intervención, la suspensión de las facultades de administración y disposición, así como el nombramiento de los administradores concursales.

\subsection{Procedimiento de mediación para conseguir el acuerdo}

\subsubsection{La iniciación del procedimiento}

En relación con la voluntariedad, para iniciarse el procedimiento, y a diferencia de un procedimiento de mediación normal, el procedimiento mediatorio que persigue la consecución del acuerdo extrajudicial de pagos se inicia por decisión del órgano competente a instancia del deudor.

La voluntariedad es un elemento básico de la mediación, que queda atemperado en el marco del procedimiento de acuerdo extrajudicial al iniciarse sin la adición, al menos en esta instancia, de la voluntad de los acreedores. Esta circunstancia, que aleja al procedimiento descrito del de mediación, supone una especialidad basada en la especial materia de conflicto, y que preserva la voluntariedad que se tiene que producir para finalizar el acuerdo.

De hecho, el procedimiento se puede interrumpir aunque no haya pasado el plazo de tres meses (dos meses en el caso de personas físicas no empresarias) en el que se habría de desarrollar el acuerdo si los acreedores de más de la mitad del pasivo no desearan continuar con las negociaciones: en el artículo 236.4 se indica que en este caso, y si el deudor se encontrara en situación de insolvencia actual o inminente, el mediador solicitará inmediatamente la declaración de concurso, y de forma análoga en el 242 bis. $1.9^{\circ}$ para personas físicas no empresarias.

\subsubsection{Actividades previas del mediador}

Según lo previsto en el artículo 234 y el 242 bis $1.5^{\circ}$. de la Ley Concursal, el mediador ha de realizar dos actividades:

- revisar la documentación aportada en los diez días siguientes a la aceptación del cargo, pudiendo solicitar al deudor que subsane;

- convocar a una reunión en los dos meses siguientes a la aceptación en la localidad del domicilio del deudor a los acreedores y al deudor, 30 días en caso de persona física no empresaria. Esta convocatoria habrá de recoger el objeto de la reunión, llegar a un acuerdo, y deberá ser acompañada de toda la información sobre los acreedores, las deudas, sus características y garantías. 


\section{Helena Soleto}

La forma de las comunicaciones habrá de asegurar la recepción, pudiendo utilizarse modalidades tradicionales como el conducto notarial o el burofax como otras más ágiles como incluso la recepción de correo electrónico, que se favorece según el apartado 2. II ${ }^{21}$.

\subsubsection{Fase de mediación}

Una vez que el mediador ha realizado las actividades previas de revisión y complementación de la información y la citación a las partes, la etapa de mediación se organiza en cuatro fases que persiguen la consecución de un acuerdo que no suponga la liquidación global de los bienes del deudor (art. 236.1. III LC) y que permita la continuación de la actividad:

1. Propuesta de acuerdo.

2. Propuesta de modificación de acreedores.

3. Segunda propuesta de acuerdo.

4. Reunión de las partes.

\subsubsection{Propuesta de acuerdo}

\section{a) Metodología de trabajo}

La mediación diseñada en la Ley Concursal es de carácter directivo o evaluativo, estilo de trabajo más adecuado para un tipo de mediación en la que el conflicto es únicamente o principalmente económico y una de las partes está formada por una pluralidad de personas.

El mediador adopta un papel activo, en dos planos: el procedimental y el material. Por una parte, es directivo como motor del procedimiento, y también es

21 "Artículo 234: 1. En los diez días siguientes a la aceptación del cargo, el mediador concursal comprobará los datos y la documentación aportados por el deudor, pudiendo requerirle su complemento o subsanación o instarle a corregir los errores que pueda haber.

En ese mismo plazo, comprobará la existencia y la cuantía de los créditos y convocará al deudor y a los acreedores que figuren en la lista presentada por el deudor o de cuya existencia tenga conocimiento por cualquier otro medio a una reunión que se celebrará dentro de los dos meses siguientes a la aceptación, en la localidad donde el deudor tenga su domicilio. Se excluirá en todo caso de la convocatoria a los acreedores de derecho público.

2. La convocatoria de la reunión entre el deudor y los acreedores se realizará por conducto notarial o por cualquier medio de comunicación, individual y escrita, que asegure la recepción.

Si constara la dirección electrónica de los acreedores por haberla aportado el deudor o facilitado aquéllos al mediador concursal en los términos que se indican en el apartado c) del artículo 235.2, la comunicación deberá realizarse a la citada dirección electrónica.

3. La convocatoria deberá expresar el lugar, día y hora de la reunión, la finalidad de alcanzar un acuerdo de pago y la identidad de cada uno de los acreedores convocados, con expresión de la cuantía del crédito, la fecha de concesión y de vencimiento y las garantías personales o reales constituidas.". 
directivo en el plano material, ya que es el principal proponente de opciones de solución.

Para ello, ha de tener conocimientos suficientes sobre el procedimiento concursal en general y estudiar a fondo la documentación aportada.

Una vez estudiada, el mediador podrá diseñar un sistema de acuerdo extrajudicial de pagos para el caso, que habrá de consensuar con el deudor.

Desde el punto de vista de la estructuración de la mediación, el mediador podrá abordar esta fase de diversas maneras: solicitando al deudor una propuesta y señalando los puntos débiles o poco susceptible de aprobarse y corrigiéndolos contando con el consenso del deudor, o bien de una forma más directiva, diseñando él mismo la propuesta y discutiendo con el deudor los inconvenientes que éste pudiera señalar, llegando a una propuesta consensuada.

Esta propuesta es por lo tanto la del mediador y la del deudor, es decir, el mediador ha de evaluar la adecuación de la propuesta, y en caso de que no se consiga una propuesta con el apoyo del deudor la mediación habrá de finalizarse y en su caso solicitar la declaración de concurso.

La propuesta de acuerdo habrá de ser enviada por el mediador a los acreedores al menos 20 días antes de la reunión, 15 días en caso de persona natural no empresaria.

\section{b) Mecanismos de reorganización de la deuda}

Aunque la Ley se refiere a una propuesta de acuerdo, entendemos que el mediador puede incluir distintas opciones para todo o en relación con algunos puntos, con el fin de que sean aceptados por la mayor parte posible de la deuda.

Para elaborar la propuesta, la Ley se refiere a diversos mecanismos para reorganizar la deuda, que pueden ser tan agresivos para la situación de los acreedores como la quita, o tan inciertos como la espera de hasta diez años o la conversión en participaciones ${ }^{22}$.

Otros mecanismos menos arriesgados para el acreedor serán la cesión de bienes o derechos en pago, que la Ley limita excluyéndola cuando impidiera la con-

${ }^{22}$ Art. 236.1:" a) Esperas por un plazo no superior a diez años.

b) Quitas.

c) Cesión de bienes o derechos a los acreedores en pago o para pago de totalidad o parte de sus créditos.

d) La conversión de deuda en acciones o participaciones de la sociedad deudora. En este caso se estará a lo dispuesto en el apartado 3.b).3. ${ }^{\circ}$ ii) de la disposición adicional cuarta.

e) La conversión de deuda en préstamos participativos por un plazo no superior a diez años, en obligaciones convertibles o préstamos subordinados, en préstamos con intereses capitalizables o en cualquier otro instrumento financiero de rango, vencimiento o características distintas de la deuda original.

Solo podrá incluirse la cesión en pago de bienes o derechos a los "acreedores siempre que los bienes o derechos cedidos no resulten necesarios para la continuación de la actividad profesional o empresarial y que su valor razonable, calculado conforme a lo dispuesto en el artículo 94.5, sea igual o inferior al crédito que se extingue. Si fuese superior, la diferencia se deberá integrar en el patrimonio del deudor. Si se tratase de bienes afectos a garantía, será de aplicación lo dispuesto por el artículo 155.4”. 


\section{Helena Soleto}

tinuación de la actividad del deudor, y con la prevención de que el bien no tuviera un valor superior al crédito que se extingue.

c) Contenido de la propuesta

La propuesta deberá incluir, según se dispone en el artículo 236.2 de la Ley Concursal, dos documentos:

- Plan de pagos.

- Plan de viabilidad.

Se detalla en el artículo 236.2 su contenido; en relación con el plan de pagos, incluirá los recursos previstos para su cumplimiento, y el plan de viabilidad contendrá la propuesta de cumplimiento de las nuevas obligaciones y el plan de continuación de la actividad, señalándose la posibilidad de incluir una cuantía mensual en concepto de alimentos para el deudor y su familia, y otras prevenciones como la previsión del pago de los créditos de derecho público.

\subsubsection{Propuesta de los acreedores}

Una vez que la propuesta del mediador y el deudor ha sido enviada a los acreedores, estos podrán presentar propuestas de modificación o incluso propuestas alterativas, que se harán llegar por la misma vía de comunicaciones en los 10 días naturales tras el envío de la propuesta por el mediador concursal.

La Ley se refiere al momento inicial de transcurso del plazo como el de envío de la propuesta del acuerdo, lo cual puede producir dificultad para elaborar la propuesta del acreedor si no se ha recibido el la propuesta del mediador en el día de su envío.

\subsubsection{Propuesta final del mediador}

Una vez que el mediador recibe las propuestas de los acreedores, habrá de estudiarlas y elaborar una nueva propuesta con la aceptación del deudor.

En cuanto al plazo en el que el mediador ha de realizar la propuesta final, aunque la Ley se refiere al plazo de 10 días posteriores al envío de la primera propuesta por parte del mediador ${ }^{23}$ para que envíe la segunda habrá de ser el restante hasta la reunión con las partes, y lo antes posible desde que ha recibido la o las propuestas de modificación, puesto que, dependiendo de la complejidad del asunto y el número de acreedores proponentes, habrá de ocupar varios días en estudiar las propuestas y elaborar una nueva que obtenga el apoyo del deudor.

\footnotetext{
${ }^{23}$ Art. 236.3 Ley Concursal.
} 


\subsubsection{Reunión de las partes}

La mediación concursal ha sido diseñada con una fase de negociación asíncrona y una sesión conjunta de todas las partes, en la que se intentará la consecución del acuerdo.

\section{a) Participantes}

En cuanto a la participación de las partes, la intención del legislador es que participen todos o que bien se manifiesten expresamente aprobando o oponiéndose a la propuesta, ya que los que no realicen esa manifestación o no acudan verán que, de pasarse a la fase de concurso, sus créditos pararán a ser subordinados, con la excepción de los créditos con garantía real.

Podrán excusar asistencia las partes que estuvieran de acuerdo con la propuesta o que por el contrario la rechacen, siempre que comuniquen en los diez días naturales anteriores a la reunión (art. 237.1 Ley Concursal).

La sesión conjunta habrá de gestionarse por el mediador con el fin de conseguir el consenso o la aprobación por la mayor parte posible de la deuda, y será entonces modificable la propuesta si bien respetando la situación de los deudores que comunicaron su aprobación y no hubieran asistido a la reunión (237.2. Ley Concursal).

La posibilidad de aprobar la propuesta y no acudir a la reunión y que se hayan de respetar los derechos de este acreedor parece que es un mecanismo para favorecer la construcción del acuerdo previamente a la reunión, otorgando mayor control del procedimiento al mediador.

b) Aprobación del acuerdo

A diferencia de la mediación regulada por la Ley de 2012, en la mediación concursal el acuerdo se puede considerar conseguido con la aceptación del deudor y los acreedores que representen un porcentaje determinado de la deuda, que será más alto si las limitaciones a los derechos de los acreedores en el acuerdo son más importantes.

La Ley Concursal establece unas mayorías calculadas sobre la totalidad del pasivo, necesarias para que el acuerdo de mediación se considere aceptado: será preciso que vote a favor una mayoría cualificada del pasivo, un $60 \%$, que habrá de ser del 75\% si en el acuerdo hay limitaciones más graves para los acreedores:

- 60 por ciento del pasivo: Los acreedores sin garantía real o con cuantías que excedan la garantía real sufrirán esperas de hasta 5 años, quitas del 25\% y conversión en préstamos participativos por el mismo plazo.

- 75 por ciento del pasivo: los mismos sufrirán esperas de hasta 10 años y quitas superiores al $25 \%$. 


\section{Helena Soleto}

En lo que toca a los deudores que tienen garantías reales, que por lo tanto tienen mayor probabilidad de cobrar, también se recoge en la Ley la posibilidad de que sufran quitas, esperas y conversión, pero únicamente (fuera de la posibilidad de que hayan llegado a un acuerdo) cuando hayan votado a favor del acuerdo acreedores que representen un porcentaje elevado de las garantías ${ }^{24}$.

c) Elevación a escritura pública y cierre del procedimiento

Como se dispone en el artículo 238.2 de la Ley Concursal, si la propuesta fuera aceptada por los acreedores, el acuerdo se elevará inmediatamente a escritura pública, que cerrará el expediente que hubieran abierto el notario, el registrador o la Cámara.

Además, se enviará a los registros competentes para que se cancelen las anotaciones publicadas, y se publicará la existencia del acuerdo en el Registro Público Concursal, que contendrá los datos del deudor, la institución competente para la iniciación del procedimiento, los datos del mediador y la circunstancia de dónde está a disposición de los acreedores el acuerdo.

\subsection{Efectos}

\subsubsection{Efectos de la iniciación del expediente}

Según lo dispuesto en el artículo 235 de la Ley Concursal, la iniciación del expediente tiene tres efectos de gran relevancia:

- el deudor pueda continuar su actividad normal;

- no se podrá declarar en concurso al deudor en dos meses;

- los acreedores no podrán iniciar ni continuar ejecución sobre bienes del deudor ni llevar a cabo actividades que mejoraran su situación acreedora;

- se suspenderá el devengo de intereses.

\subsubsection{La continuación de la actividad por parte del deudor}

En el artículo 235.1 se indica que a partir de la solicitud de apertura del expediente el deudor podrá continuar con su actividad laboral, empresarial o profesional, lo que permite que no tenga que interrumpirla hasta que la institución nombre mediador, únicamente con la presentación de solicitud está legitimado para ello.

Esta actividad, si bien autorizada, no debe exceder el tráfico de su actividad: "Desde la presentación de la solicitud, el deudor se abstendrá de realizar cualquier

\footnotetext{
${ }^{24} \mathrm{Vid}$. apartado correspondiente a efectos del acuerdo.
} 
acto de administración y disposición que exceda los actos u operaciones propias del giro o tráfico de su actividad".

\subsubsection{Imposibilidad de declarar el concurso durante tres meses}

En el apartado quinto del artículo 235 se dispone que "El deudor que se encontrase negociando un acuerdo extrajudicial no podrá ser declarado en concurso, en tanto no transcurra el plazo previsto en el artículo 5 bis.5.", y este plazo es de tres meses desde la comunicación al juzgado, y que tiene como finalizar dar un espacio temporal de 3 meses como máximo para llegar a un acuerdo en el procedimiento mediatorio.

\subsubsection{Congelación de actividad ejecutiva del acreedor}

Para posibilitar que las negociaciones tengan espacio, se paraliza la ejecución judicial o extrajudicial por un plazo máximo de 3 meses, con excepción de los que tuvieran una garantía real que no recaiga sobre bienes o derechos que resulten necesarios para la continuidad de la actividad profesional o empresarial del deudor ni sobre su vivienda habitual, caso en el que si bien podrán ejercitar la acción real, se paralizará el procedimiento durante el plazo máximo de 3 meses.

El momento desde el que se produce esta congelación es desde que se comunica al juez competente del concurso la iniciación del procedimiento de acuerdo.

Además deberán abstenerse de realizar actos dirigidos a mejorar su situación respecto al deudor, y deberán facilitar un correo electrónico para recibir comunicaciones, al que producirán plenos efectos.

Por otra parte, no podrán realizarse anotaciones en los registros públicos de bienes a partir de que se realice la anotación de apertura del procedimiento, con la excepción de los instados por acreedores de derecho público.

\subsubsection{Congelación de intereses}

Tal como se establece en el artículo 235.3, "durante el plazo de negociación del acuerdo extrajudicial de pagos y respecto a los créditos que pudieran verse afectados por el mismo, se suspenderá el devengo de intereses de conformidad con lo dispuesto por el artículo 59".

Ante la falta de concreción normativa de la fecha de inicio del periodo de suspensión del devengo de intereses, podríamos referirnos a la fecha de la solicitud, a la de la iniciación del procedimiento o a la de la comunicación al juzgado, y parece la más adecuada puede ser la fecha de inicio del procedimiento, que corresponde con el nombramiento del mediador por parte de la institución correspondiente (Registrador, Notario o Cámara). 


\section{Helena Soleto}

\subsubsection{Efectos del acuerdo}

El acuerdo extrajudicial, si se cumplen las mayorías establecidas por la Ley, no será rescindible en un futuro procedimiento concursal (art. 238.4), y tendrá efectos sobre la situación de acreedores que no hubieran participado o dado su consentimiento en el acuerdo, concretamente (art. 240):

1. No podrán iniciar o continuar ejecuciones contra el deudor por deudas anteriores a la apertura del expediente.

2. Los créditos quedan aplazados, remitidos o extinguidos conforme a lo acordado.

El acuerdo aprobado con las mayorías establecidas afecta a los acreedores sin garantía real, incluso aunque no hubieran dado su acuerdo o incluso se opusieran a la propuesta de acuerdo, pero también se puede extender a acreedores con garantía real si una mayoría cualificada de acreedores con deuda asegurada por garantía real apoyara el acuerdo:

- si el 65\% de la garantía real otorgada apoya el acuerdo, a los acreedores con garantía real se les podrán aplicar reducciones quitas, esperas y conversiones como las del apartado a) del artículo 238.1.

- el porcentaje habrá de ser del $80 \%$ para que se apliquen las medidas del apartado b) del mismo artículo 238.1.

Estas extensiones subjetivas, según son calificadas por el art. 238 bis., tienen un contenido análogo al del artículo 238 pero se refieren a acreedores con garantías reales, que quedan fuera de la influencia del acuerdo si no dan su consentimiento al acuerdo, con la excepción de que una mayoría cualificada de la garantía real apoyara el acuerdo, con la posibilidad de que se puedan limitar los derechos del acreedor en el mismo sentido que los acreedores sin garantía real.

El legislador ha elegido regularlo en un artículo separado, sin embargo sería más adecuado haberlo incluido en el artículo relativo al acuerdo, pues la dicción del artículo 238 bis parece que regula la extensión a partir del acuerdo de sus efectos, pero en realidad regula el contenido del acuerdo y las mayorías cualificadas de los créditos con garantía real para que se pueda producir alguna limitación para sus derechos de crédito.

Esta posible limitación de los derechos no se producirá nunca respecto de los acreedores públicos, tampoco cuando tenga garantía real, según se dispone en el artículo 231.5.

3. Se mantienen los derechos frente a los obligados solidariamente, fiadores y avalistas, siempre que los acreedores no hubieran aceptado o se opusieran al acuerdo.

En general, la situación de las personas que hubieran otorgado garantía personal en alguno de los créditos no se verá afectada por el procedimiento de acuerdo: 
en el artículo 240 LC se señala que la situación de terceros que sean obligados, fiadores o avalistas dependerá de si hubiera sido o no aceptado el acuerdo por el acreedor: si no hubiera sido aceptado, se mantendrán sus derechos frente a estos terceros, y si lo hubiera aceptado, dependerá de los términos de la respectiva relación jurídica. Además, en el artículo 235.4 se indica que el acreedor tiene abierta la posibilidad de ejercitar la garantía personal desde el vencimiento sin que afecte el inicio del procedimiento de acuerdo.

\subsection{Recursos y cumplimiento}

De acuerdo con lo establecido en el artículo 239 LC, el acuerdo podrá ser impugnado por el acreedor que no hubiera sido convocado o no hubiera votado a favor del acuerdo o hubiera manifestado con anterioridad su oposición ante el juzgado que fuera competente para conocer del concurso.

La impugnación no suspenderá la ejecución del acuerdo y solo podrá fundarse en la falta de concurrencia de las mayorías exigidas, en la superación de los límites establecidos por el artículo 236.1 o en la desproporción de las medidas acordadas, y se tramitará conjuntamente por el procedimiento del incidente concursal, y la sentencia de anulación del acuerdo será susceptible de recurso de apelación de tramitación preferente.

En caso de que el acuerdo se anule, se iniciará el concurso consecutivo, lo que ocurrirá también si no se cumple el acuerdo.

El mediador ha de supervisar el cumplimiento del acuerdo. En caso de cumplirse el acuerdo, el mediador lo hará constar en un acta notarial que se publicará en el Registro Público Concursal.

Por el contrario, si el acuerdo extrajudicial de pagos fuera incumplido, el mediador concursal deberá instar el concurso consecutivo.

\section{EL CONCURSO CONSECUTIVO}

La Ley Concursal ha otorgado al mediador concursal la posibilidad de instar el concurso consecutivo y convertirse en administrador concursal cuando el acuerdo fuera anulado, cuando no fuera posible llegar a un acuerdo o cuando el acuerdo sea incumplido.

También puede iniciarse el concurso consecutivo a solicitud del deudor o de los acreedores (art. 242.1).

En el concurso consecutivo el mediador es nombrado administrador concursal como regla ("Salvo justa causa, el juez designará administrador del concurso al mediador concursal"), y no podrá percibir honorarios superiores a los determinados para ser mediador. 


\section{Helena Soleto}

Se establece que cesa la obligación de confidencialidad del mediador, puesto que ya deja de serlo, lo que no afecta a lo ya conocido como mediador; la información que hubiera conocido en tanto mediador, habrá de quedar protegida por el deber de confidencialidad.

Ya nos hemos referido a que esta posibilidad de continuar siendo administrador concursal por parte del mediador lo convierte en una figura híbrida, análoga a la del medarb ${ }^{25}$, y que trastoca de alguna manera los planteamientos generales estratégicos, pudiendo afectar incluso a la fase de mediación.

Evidentemente, el objetivo del concurso consecutivo es la administración y liquidación lo más rápida y eficaz posible bajo la dirección del profesional que ya ha conocido el asunto como mediador, y ello apoya el diseño de esta novedosa figura, pues las ventajas pueden ser mucho mayores a los inconvenientes.

Consideramos que se trata de una mediación muy estructurada normativamente, que no se alinea con la tan alabada virtud de la flexibilidad de la mediación $^{26}$, en la que el mediador tiene unos poderes directivos y evaluativos ${ }^{27}$ que no observamos en las mediaciones civiles en general, pero que no la apartan de ser una forma de mediación adecuada en este especial ámbito.

\section{CONCLUSIONES}

El procedimiento diseñado en la Ley Concursal corresponde a un sistema de mediación muy estructurada, con importantes competencias directivas del mediador, y que extiende su resultado a personas que no participaron o no estuvieron de acuerdo con el acuerdo.

Es novedoso en nuestro sistema la creación de la fórmula híbrida de resolución de conflictos que se ha creado, del mediador concursal seguido de administrador, y, pese a los claroscuros que pueda presentar la competencia, nombramiento y remuneración de los participantes, esperemos que sea un mecanismo que tenga éxito, tanto en el ámbito empresarial como en el privado, que los operadores actúen con transparencia, profesionalidad y diligencia y se procure el mantenimiento de las actividades empresariales, profesionales y los hogares españoles tengan un mecanismo positivo para hacer frente a la crisis.

\footnotetext{
${ }^{25}$ Vid. apartado 2.3.

${ }^{26}$ Górriz López, C., "Mediación concursal”, Diario La Ley, (núm. 8384, 2014), p. 11, se refiere a esta circunstancia, sin que ello suponga que la institución no sea mediación.

${ }^{27}$ Prats Albentosa, L., "La mediación en el pre-concurso", Revista de Mediación, (vol. 7, núm.1, 2014) p. 77, señala que "la norma reserva al mediador un amplio y muy importante ámbito para que despliegue sus particulares habilidades profesionales durante las sesiones a celebrar entre el deudor y sus acreedores, a fin de afrontar con éxito la superación del problema”.
} 


\section{BIBLIOGRAFÍA}

ENCISO ALONSO-MUNUUMER, M. T., "Acuerdo extrajudicial de pagos y segunda oportunidad”, en VV. AA., La Ley concursal y la Mediación Concursal: un estudio conjunto realizado por especialistas, Dykinson, Madrid, 2014.

GÓRRIZ LÓPEZ, C.,"Mediación concursal”, Diario La Ley, (núm. 8384, 2014)

MERINO ESPINAR, M. B., "Una primera aproximación a la realidad del acuerdo extrajudicial de pagos y la figura del mediador concursal y su relación con el Registro de la Propiedad", Revista de Derecho Civil, (vol II, núm. 1, enero 2015).

ORDEÑANA, I., "El fin justifica...La mediación concursal empresarial o profesional: sobre la función y regulación de este mecanismo extrajurisdiccional en el derecho español", en Barona Vilar, S., (coord.), Mediación, arbitraje y jurisdicción en el actual paradigma de justicia, Thomson ReutersCivitas, Pamplona, 2016, pp. 119-145.

ORTIZ HERNÁNDEZ, A., "La mediación en el concurso de acreedores", Diario la Ley, (núm. 8111, 2013).

PRATS ALBENTOSA, L., "La mediación en el pre-concurso", Revista de Mediación, (vol. 7, núm.1, 2014).

PRATS ALBENTOSA, L., "La mediación (pre)-concursal", Diario La Ley, (núm. 8264, 2014).

RISKIN, L., "Decisionmaking in Mediation: The New Old Grid and the New New Grid System", Notre Dame Law Review, (vol. 79, núm. 1, 2003).

RODRÍGUEZ PRIETO, F., "El acuerdo extrajudicial de pagos desde la perspectiva del notario", en VV. AA., La Ley concursal y la Mediación Concursal: un estudio conjunto realizado por especialistas, Dykinson, Madrid, 2014.

SOLETO MUÑOZ, H., "El procedimiento de mediación”, en Soleto Muñoz, H. (dir.), Carretero Morales, E. y Ruiz López, C. (coord..), Mediación y solución de conflictos: técnicas y ámbitos, Tecnos, Madrid, 2013.

SANJUAN MUÑOZ, E., "La naturaleza jurídica del mediador concursal: sistema alternativo de gestión de los supuestos de insolvencia”, Diario la Ley, (núm. 8230, 2014).

SENÉS MOTILLA, C., "El acuerdo extrajudicial de pagos: ¿alternativa efectiva al concurso de acreedores?", Revista de Derecho Civil, (núm.1, eneromarzo 2014). 